https://helda.helsinki.fi

\title{
Low-Temperature Wafer-Scale Deposition of Continuous 2D SnS2 Films
}

\section{Mattinen, Miika}

2018-05-24

Mattinen , M , King , P J , Khriachtchev , L , Meinander , K, Gibbon , J T , Dhanak , V R, Räisänen , J , Ritala , M \& Leskelä , M 2018 , ' Low-Temperature Wafer-Scale Deposition of Continuous 2D SnS2 Films ' , Small , vol. 14 , no. 21 , 1800547 . https://doi.org/10.1002/smll.201800547

http://hdl.handle.net/10138/302076

https://doi.org/10.1002/smll.201800547

acceptedVersion

Downloaded from Helda, University of Helsinki institutional repository.

This is an electronic reprint of the original article.

This reprint may differ from the original in pagination and typographic detail.

Please cite the original version. 


\section{WILEY-VCH}

DOI: $10.1002 / \mathrm{smll} .201800547$

Article type: Full Paper

"This is the peer reviewed version of the following article:Mattinen et al., Small, 14, 2018, 1800547, which has been published in final form at https://doi.org/10.1002/smll.201800547. This article may be used for non-commercial purposes in accordance with Wiley Terms and Conditions for Use of Self-Archived Versions."

\section{Low-Temperature Wafer-Scale Deposition of Continuous 2D $\mathrm{SnS}_{2}$ Films}

Miika Mattinen, Peter J. King, Leonid Khriachtchev, Kristoffer Meinander, James T. Gibbon, Vin R. Dhanak, Jyrki Räisänen, Mikko Ritala, ${ }^{*}$ Markku Leskelä

M. Mattinen, Dr. P. J. King, Dr. L. Khriachtchev, Prof. M. Ritala, Prof. M. Leskelä

Department of Chemistry, University of Helsinki, P.O. Box 55, FI-00014, Finland

E-mail: mikko.ritala@helsinki.fi

Dr. K. Meinander, Prof. J. Räisänen

Division of Materials Physics, Department of Physics, University of Helsinki, P.O. Box 43, FI-00014, Finland

J. T. Gibbon, Dr. V. R. Dhanak

Stephenson Institute for Renewable Energy and Department of Physics, University of Liverpool, Liverpool L69 7ZF, United Kingdom

Keywords: 2d materials, atomic layer deposition, thin films, semiconductors, $\mathrm{SnS}_{2}$

Semiconducting 2D materials, such as $\mathrm{SnS}_{2}$, hold immense potential for many applications ranging from electronics to catalysis. However, deposition of few-layer $\mathrm{SnS}_{2}$ films has remained a great challenge. Herein, continuous wafer-scale $2 \mathrm{D} \mathrm{SnS}_{2}$ films with accurately controlled thickness ( 2 to 10 monolayers) are realized by combining a new atomic layer deposition process with low-temperature $\left(250^{\circ} \mathrm{C}\right)$ post-deposition annealing. Uniform coating of large-area and three-dimensional substrates is demonstrated owing to the unique selflimiting growth mechanism of atomic layer deposition. Detailed characterization confirms the 1T-type crystal structure and composition, as well as smoothness and continuity of the $\mathrm{SnS}_{2}$ films. A two-stage deposition process is also introduced to improve the texture of the films. Successful deposition of continuous, high-quality $\mathrm{SnS}_{2}$ films at low temperatures constitutes a crucial step towards various applications of 2D semiconductors. 


\section{WILEY-VCH}

\section{Introduction}

Two-dimensional (2D) materials have attracted a great deal of attention since the seminal 2004 paper on semimetallic graphene. ${ }^{[1]}$ In particular, semiconducting 2D materials have rapidly gained interest after the 2011 report on $\mathrm{MoS}_{2}$ as a high-performance channel material in field-effect transistors (FETs). ${ }^{[2]}$ Recently, tin disulfide $\left(\mathrm{SnS}_{2}\right)$ has emerged as a highly promising 2D semiconductor. While tin is not a transition metal, $\mathrm{SnS}_{2}$ shares the $\mathrm{MX}_{2}$ composition and layered crystal structure with the well-known transition metal dichalcogenides (TMDCs), ${ }^{[3,4]}$ and has an indirect band gap of approximately $2.2 \mathrm{eV}$ in bulk $^{[5,6]}$ and $2.6 \mathrm{eV}$ in monolayer form. ${ }^{[7]} \mathrm{SnS}_{2}$ has shown performance comparable to $\mathrm{MoS}_{2}$, the most widely studied TMDC, in FETs ${ }^{[4,8]}$ and photodetectors. ${ }^{[4,9]}$ In addition, $2 \mathrm{D} \mathrm{SnS}_{2}$ has been studied for water-splitting catalysis, ${ }^{[10]}$ thermoelectrics, ${ }^{[11]}$ batteries, ${ }^{[12]}$ and gas sensing ${ }^{[13]}$ applications, for example.

The requirements for accurate film thickness control and uniformity over large, wafer-level areas are major challenges hindering the use of $\mathrm{SnS}_{2}$ and other $2 \mathrm{D}$ materials on industrial level. ${ }^{[14]}$ Low processing temperatures are also desirable to ensure compatibility with the wide range of substrates and other thin film layers needed to realize various applications. In addition, many industrially relevant device structures, such as FETs and random-access memory cells, are highly three-dimensional, and thus difficult to coat uniformly. ${ }^{[15,16]}$ These issues pose heavy demands on film deposition and have so far not been met for $2 \mathrm{D} \mathrm{SnS}_{2}$.

Micromechanical exfoliation of bulk crystals, the original method used to produce graphene, can produce high-quality sheets of $\mathrm{SnS}_{2}$ as well, ${ }^{[4,8]}$ but suffers from abysmal throughput and poor control over the size and thickness of $\mathrm{SnS}_{2}$ sheets, and is thus mainly suited for fundamental studies. ${ }^{[3,17]}$ Liquid exfoliation $^{[18]}$ and hydrothermal synthesis ${ }^{[19]}$ of $\mathrm{SnS}_{2}$ offer good scalability, but still produce flakes instead of continuous films and have limited control over their size and thickness. 


\section{WILEY-VCH}

Gas-phase synthesis methods, such as chemical vapor deposition (CVD) and atomic layer deposition (ALD) offer the best control for the deposition of 2D materials. Although CVD is quite well established in academic research for the most studied TMDCs, ${ }^{[20-23]}$ such as $\mathrm{MoS}_{2}$ and $\mathrm{WSe}_{2}$, reports on wafer-scale deposition of continuous films are still scarce. ${ }^{[24,25]}$ To date, CVD has been unable to produce continuous $\mathrm{SnS}_{2}$ films, with only a few reports of $2 \mathrm{D}(<10$ $\mathrm{nm}) \mathrm{SnS}_{2}$ flakes published to date. ${ }^{[7,9,26-28]}$ Additionally, these CVD processes operate at elevated temperatures of at least $450{ }^{\circ} \mathrm{C}^{[28]}$ or even $580-700{ }^{\circ} \mathrm{C} \cdot{ }^{[7,9,26,27]}$

ALD is a gas-phase thin film deposition technique that may be regarded as an advanced modification of CVD. Contrary to traditional CVD, in ALD the precursors are pulsed to the substrates alternately, and they are not allowed to decompose on their own. As a result, the film growth proceeds by self-limiting surface reactions only. ${ }^{[29-31]}$ Consequently, ALD offers unprecedented ability to coat large areas (uniformity) and complex shapes (conformality). In addition, the film thickness is accurately controlled by varying the number of deposition cycles. Other advantages stemming from the self-limiting reactions include excellent reproducibility and scalability, and relatively low deposition temperatures, typically 100 to $400{ }^{\circ} \mathrm{C}$. These benefits have led to the use of ALD in semiconductor and other industries. ${ }^{[32,33]}$ However, successful use of ALD relies on finding precursors fulfilling stringent requirements, such as high reactivity and thermal stability. ${ }^{[29,31]}$

So far, only a single research group has deposited $\mathrm{SnS} \mathrm{S}_{2}$ by $\mathrm{ALD}$ using $\mathrm{Sn}\left(\mathrm{NMe}_{2}\right)_{4}$ and $\mathrm{H}_{2} \mathrm{~S}$ as precursors at $150{ }^{\circ} \mathrm{C}^{[34,35]}$ with improved film quality achieved through post-deposition annealing in $S^{[36,37]}$ or $\mathrm{H}_{2} \mathrm{~S}^{[38]}$ atmosphere. Nevertheless, many crucial features of film deposition, including conformality, uniformity, and thickness control have not been demonstrated for $2 \mathrm{D} \mathrm{SnS}_{2}$ films.

Here, we report the deposition of continuous wafer-scale $2 \mathrm{D} \mathrm{SnS}_{2}$ films for the first time. Our scalable and industrially compatible low-temperature method combines ALD and mild postdeposition annealing in a single vacuum chamber. The amorphous $\mathrm{SnS}_{2}$ films deposited using 


\section{WILEY-VCH}

a new tin precursor, tin(IV) acetate, and $\mathrm{H}_{2} \mathrm{~S}$ at $150{ }^{\circ} \mathrm{C}$ crystallize upon annealing in $\mathrm{H}_{2} \mathrm{~S} / \mathrm{N}_{2}$ atmosphere at $250{ }^{\circ} \mathrm{C}$. After annealing, continuous, smooth, stoichiometric, and crystalline $\mathrm{SnS}_{2}$ films are obtained with an accurately controlled thickness from two to ten monolayers (1.2 to $6 \mathrm{~nm})$, wafer-scale $\left(5 \times 5 \mathrm{~cm}^{2}\right)$ uniformity, and good conformality on 3D trench structures. Systematic deposition experiments and full film characterization are presented to advance the research on the emerging 2D semiconductor $\mathrm{SnS}_{2}$ and other $2 \mathrm{D}$ materials. 


\section{WILEY-VCH}

\section{Results and Discussion}

\subsection{Film Growth}

Crystalline $\mathrm{SnS}_{2}$ films with thickness from two to ten monolayers (ML) were deposited by $\mathrm{ALD}$ at $150{ }^{\circ} \mathrm{C}$ using sequential pulses of $\mathrm{Sn}(\mathrm{OAc})_{4}$ and $\mathrm{H}_{2} \mathrm{~S}$ followed by post-deposition annealing at $250{ }^{\circ} \mathrm{C}$ in the ALD reactor (Figure 1a). Of the five tin precursors evaluated (see Supporting Information), only $\mathrm{Sn}(\mathrm{OAc})_{4}$, a new ALD precursor, yielded satisfying growth characteristics. In ALD, film growth proceeds through self-limiting surface reactions of the alternately pulsed precursors, $\mathrm{Sn}(\mathrm{OAc})_{4}$ and $\mathrm{H}_{2} \mathrm{~S}$ (steps $\mathrm{i}$ and iii in Figure 1a), each pulse being separated by a $\mathrm{N}_{2}$ purge step (steps ii and iv in Figure 1a) to eliminate gas-phase reactions. This guarantees excellent control in film deposition, which is exemplified by the excellent uniformity of films deposited on $5 \times 5 \mathrm{~cm}^{2}$ substrates comparable to commonly used 2" wafers (Figure 1b). The substrate size was limited by the research-scale equipment used in this work. Commercial ALD equipment exists for coating 12“wafers or even larger substrates as well as batches of over 100 wafers, ${ }^{[1,39]}$ which allow further upscaling of the present process. The as-deposited $\mathrm{SnS}_{2}$ films were amorphous, and crystallized upon annealing forming smooth, continuous films with the expected layered $\mathrm{SnS}_{2}$ structure (Figure 1c,d). ${ }^{[40,41]}$ Self-limiting surface reactions characteristic to ALD were confirmed by observing the saturation of the growth rate when $\mathrm{Sn}(\mathrm{OAc})_{4}$ and $\mathrm{H}_{2} \mathrm{~S}$ pulses of at least 0.2 and $2 \mathrm{~s}$, respectively, were used (Figure 2a). Similarly, saturation of the growth rate implies that a $2 \mathrm{~s}$ purge after each precursor pulse was sufficient to remove the unreacted precursor and byproducts (Figure $2 \mathrm{~b}$ ). To benefit from the advantages of ALD, saturated pulse lengths of $1 \mathrm{~s}$ $\left(\mathrm{Sn}(\mathrm{OAc})_{4}\right)$ and $4 \mathrm{~s}\left(\mathrm{H}_{2} \mathrm{~S}\right)$ and $2 \mathrm{~s}$ purges were used in the following experiments. 


\section{a)}
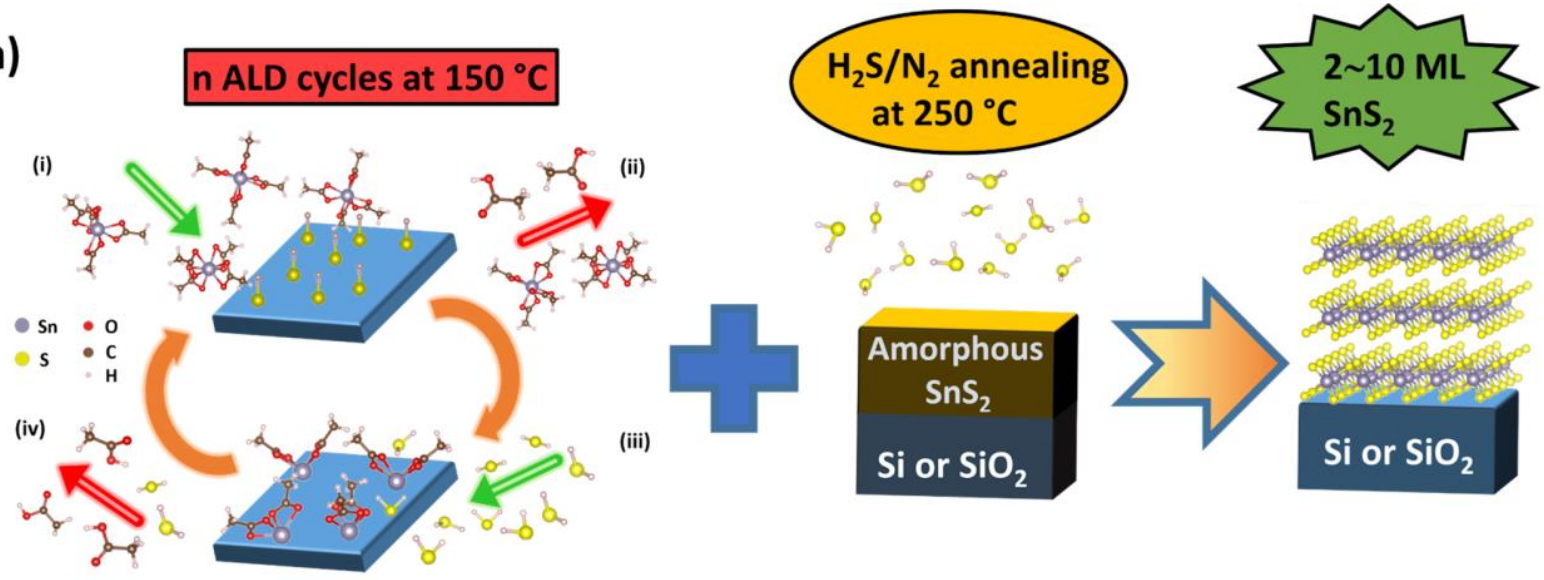

b)

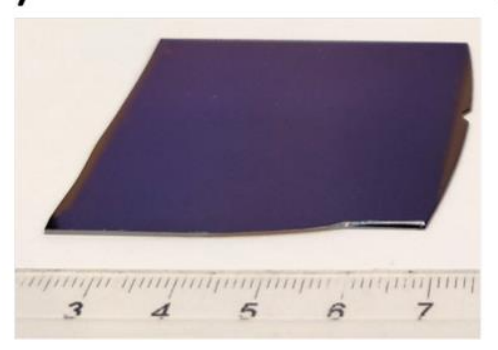

c)

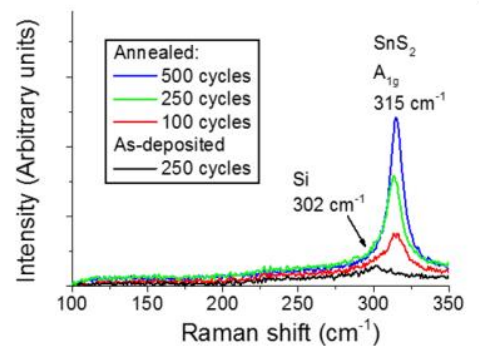

d)

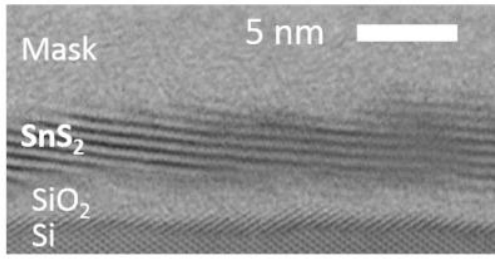

Figure 1. Large-area deposition of few-layer $\mathrm{SnS}_{2}$ films. a) Schematic illustration of the $\mathrm{SnS}_{2}$ deposition and annealing procedure. b) Photograph of a $3.5 \mathrm{~nm}$ thick $\mathrm{SnS}_{2}$ film (250 cycles, annealed) with a uniform thickness (color) over the $5 \times 5 \mathrm{~cm}^{2} \mathrm{SiO}_{2} / \mathrm{Si}$ substrate. Narrow strips on each side of the substrate were blocked by the substrate holder during the deposition and thus reveal the bare substrate. c) Raman spectra of $\mathrm{SnS}_{2}$ films deposited on $\mathrm{SiO}_{2} / \mathrm{Si}$ substrate before and after $\mathrm{H}_{2} \mathrm{~S}$ annealing. The $\mathrm{SnS}_{2}$ peak assignment is from ref. 42 and the $302 \mathrm{~cm}^{-1}$ feature originates from the Si substrate. d) Bright-field cross-sectional transmission electron microscopy (XTEM) image of a $3.5 \mathrm{~nm}$ thick $\mathrm{SnS}_{2}$ film (250 cycles, annealed) on native-oxide covered silicon substrate.

The saturated growth rate was approximately $0.17 \AA$ Acycle for the as-deposited films (1000 cycles). X-Ray reflectivity (XRR) measurements indicated that in addition to crystallizing the films, $\mathrm{H}_{2} \mathrm{~S} / \mathrm{N}_{2}$ annealing at $250{ }^{\circ} \mathrm{C}$ decreased the film thickness by about $35 \%$ and increased the density by $30 \%$ to the $\mathrm{SnS}_{2}$ bulk density ${ }^{[43]}$ of $4.5 \mathrm{~g} / \mathrm{cm}^{3}$. Thus, the growth rate was 0.11 $\AA$ A/cycle for the 1000 cycle films after the heat treatment. The deposition temperature was limited to a relatively narrow range around $150{ }^{\circ} \mathrm{C}$ (Figure S4, Supporting Information), and $250{ }^{\circ} \mathrm{C}$ was found to be the optimal annealing temperature, as discussed in the Supporting Information.

The film thickness was adjusted in the few-layer regime by simply varying the number of ALD cycles as shown in Figure 2c. Notably, the growth rate was greater during the first tens of ALD cycles before it reached a stable value after approximately 200 cycles (Figure S5, 


\section{WILEY-VCH}

Supporting Information), which suggests substrate-enhanced growth. ${ }^{[44]}$ A 100 cycle film, for example, had a thickness of approximately $2 \mathrm{~nm}$ after annealing, resulting in effectively double the growth rate compared to 1000 cycle films.

The films were highly uniform with a thickness non-uniformity of $4.2 \%$ over a $5 \times 5 \mathrm{~cm}^{2} \mathrm{Si}$ substrate (Figure 2d and Figure S6, Supporting Information). Although this level of uniformity already greatly surpasses the majority of reports for 2D materials, we anticipate that the uniformity can be further improved using production-scale ALD reactors, as the design of the cross-flow research tool ${ }^{[45]}$ used in this work is known to increase film nonuniformity for reasons such as inlet effects and byproduct readsorption. ${ }^{[29]}$

The ability to conformally coat $3 \mathrm{D}$ substrates, another unique and crucial perk of ALD that is very rarely reported for $2 \mathrm{D}$ materials, was proven using nanoscale trench structures with a depth of $90 \mathrm{~nm}$ and a width of approximately $30 \mathrm{~nm}$ (aspect ratio of 3:1). As seen in Figure 2e, the structures were coated by a crystalline $\mathrm{SnS}_{2}$ film all around, although the film at the bottom of the trenches was thicker compared to the other parts of the structure. Further discussion of the conformality as well as TEM-EDS maps and higher magnification XTEM images are presented in the Supporting Information. 
WILEY-VCH
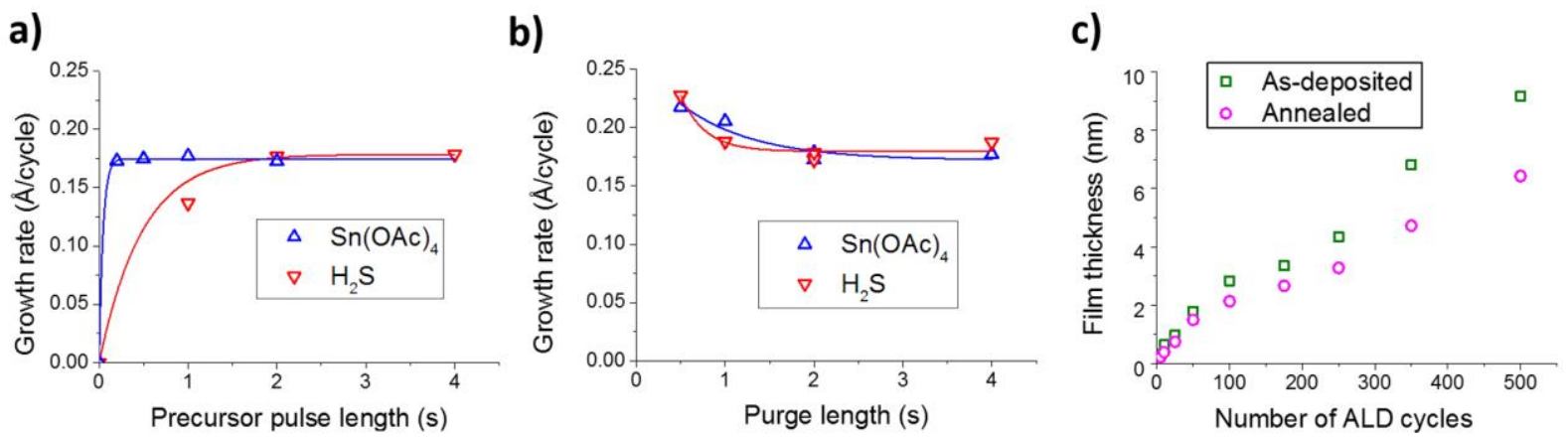

d)

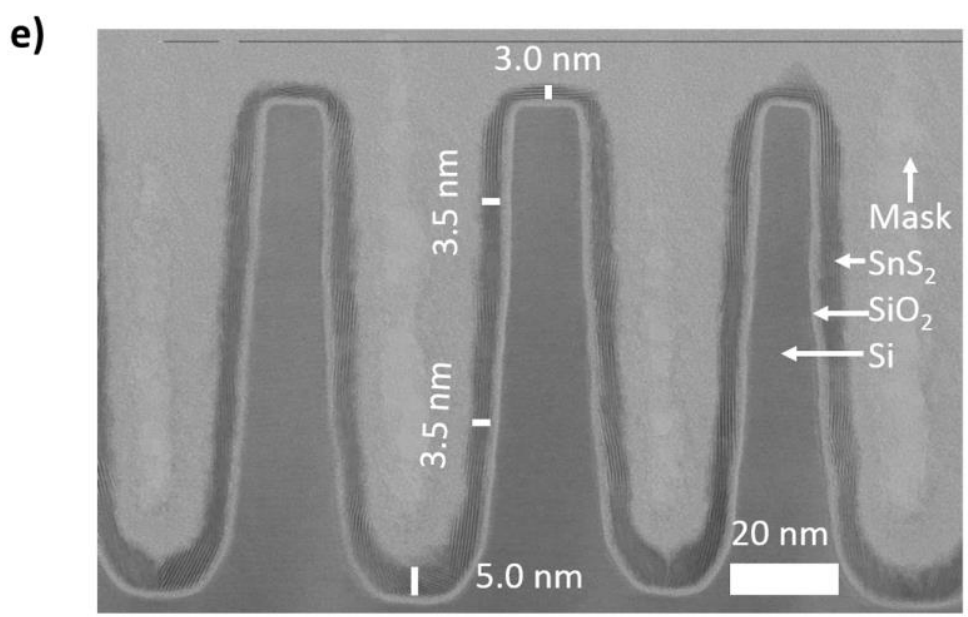

Figure 2 Characterization of film growth. Film growth rate versus a) precursor pulse and b) purge lengths. c) Film thickness versus number of ALD cycles for as-deposited and annealed films. d) Ellipsometry thickness map of a $\mathrm{SnS}_{2}$ film (annealed, 250 cycles) deposited on $5 \times 5 \mathrm{~cm}^{2} \mathrm{Si}$ substrate $(0.5 \mathrm{~cm}$ edge exclusion). e) Bright-field XTEM image of a $\mathrm{SnS}_{2}$ film deposited on a trench substrate (annealed, 250 cycles). In a) and b), unless otherwise noted, 1000 cycles were used with pulse lengths of $1 \mathrm{~s}$ for $\mathrm{Sn}(\mathrm{OAc})_{4}, 4 \mathrm{~s}$ for $\mathrm{H}_{2} \mathrm{~S}$ and $2 \mathrm{~s}$ purges, the thicknesses refer to as-deposited films, and the lines are meant to guide the eye. The film thicknesses were measured by XRR (a,b), ellipsometry (c,d), and XTEM (e).

\subsection{Structural Characterization}

Following the optimization of the annealing conditions (see Supporting Information), we characterized an approximately $10 \mathrm{ML} \mathrm{SnS} 2$ film annealed at $250{ }^{\circ} \mathrm{C}$ in $\mathrm{H}_{2} \mathrm{~S} / \mathrm{N}_{2}$ atmosphere. The film remained smooth and crystallized in the layered $\mathrm{SnS}_{2}$ structure upon annealing as shown in Figure 3a. Atomic resolution high-angle annular dark-field scanning transmission electron microscopy (HAADF-STEM) images of selected areas of the film confirmed atomic arrangement corresponding to the $1 \mathrm{~T}-\mathrm{SnS}_{2}$ structure (Figure 3b,c; see also Figure $\mathrm{S} 17$, Supporting Information). Furthermore, TEM showed the $\mathrm{SnS}_{2}$ layers to be tilted in many of the observed grains by approximately $10^{\circ}$ with respect to the substrate. The crystallinity and the presence of only the $\mathrm{SnS}_{2}$ phase was further confirmed by Raman spectroscopy (Figure S9a, Supporting Information) and X-ray diffraction (XRD, Figure S9b, Supporting 


\section{WILEY-VCH}

Information). We estimated the grain size to be a few tens of nanometers based on the XTEM images, which agrees well with the values of $20-30 \mathrm{~nm}$ obtained from the in-plane XRD data (Figure S21, Supporting Information) using the Scherrer equation. It is expected that the grain size can be increased by tailoring the annealing conditions, such as atmosphere, heating rate, annealing time, and pressure.

The out-of-plane orientation, that is the orientation of the crystallites perpendicular to the substrate, was probed by an in-plane pole figure measurement on the (001) reflection of $\mathrm{SnS}_{2}$ (Figure 3d). The resulting ring close to $\alpha=80^{\circ}\left(\alpha=90^{\circ}\right.$ is defined as the middle of the pole figure) means that in most grains the (001) basal planes were tilted by approximately $10^{\circ}$ with respect to the substrate surface. The diffuse ring near $\alpha=0^{\circ}$ is due to air scattering. In-plane $\phi$ scans (not shown) revealed no preferred in-plane orientation (orientation parallel to the substrate), as expected for substrates covered with an amorphous $\mathrm{SiO}_{2}$ layer.

X-ray photoelectron spectroscopy (XPS) measurements of $\mathrm{Sn} 3 \mathrm{~d}_{5 / 2}$ (Figure $3 \mathrm{e}$ ) and $\mathrm{S} 2 \mathrm{p}$ (Figure 3f) core-levels showed features in agreement with previous reports on $\mathrm{SnS}_{2}$ single crystals $^{[46,47]}$ and ALD thin films ${ }^{[37]}$ with binding energies of $486.5 \mathrm{eV}$ and $161.5 \mathrm{eV}$ for the Sn $3 \mathrm{~d}_{5 / 2}$ and $\mathrm{S} 2 \mathrm{p}_{3 / 2}$ peaks, respectively. The absence of notable $\mathrm{SnO}_{2}$ component at 487.2 $\mathrm{eV}^{[46]}$ in the unsputtered, air-exposed sample highlights the stability of the films towards oxidation.

The band gap was determined to be $2.35 \pm 0.14 \mathrm{eV}$ using a combination of XPS and inverse photoemission spectroscopy (IPES) measurements (Figure 3g). Band gap is the energy difference between the valence band maximum (VBM) and conduction band minimum (CBM) levels, which were determined by a linear extrapolation of the edges of the valence band (VB) and the conduction band (CB), respectively, to the background level. The obtained value is between those reported for the indirect band gap of bulk $(2.2 \mathrm{eV})^{[5,6,48]}$ and monolayer $(2.6 \mathrm{eV})^{[7]} \mathrm{SnS}_{2}$, which is reasonable considering the film thickness of approximately $10 \mathrm{ML}$. 


\section{WILEY-VCH}

Furthermore, the position of the Fermi level, which lies closer to the CB than the VB, is in line with the expected ${ }^{[8,36,46]}$ n-type nature of $\mathrm{SnS}_{2}$ films, and the band structure probed by VB-XPS was comparable to previously measured $\mathrm{SnS}_{2}$ single crystal. ${ }^{[46]}$

a)

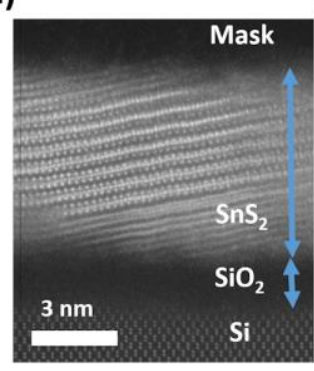

b)

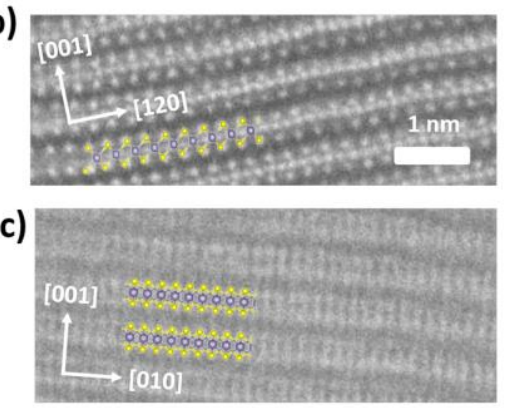

d)

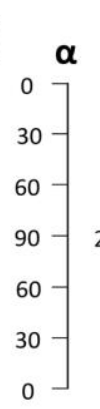

S 2p f)

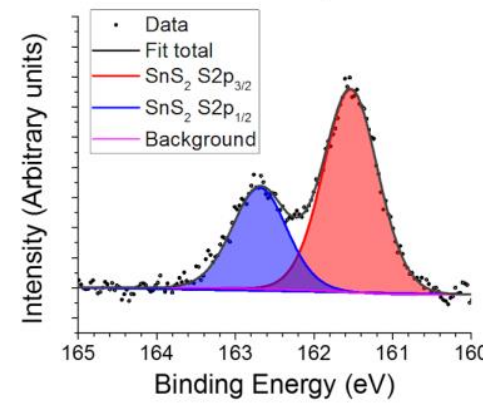

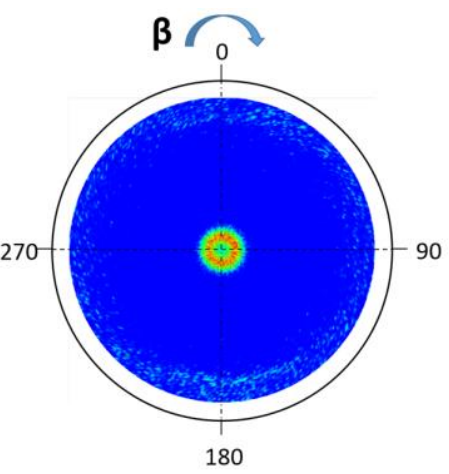

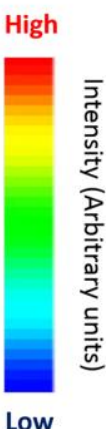

g)

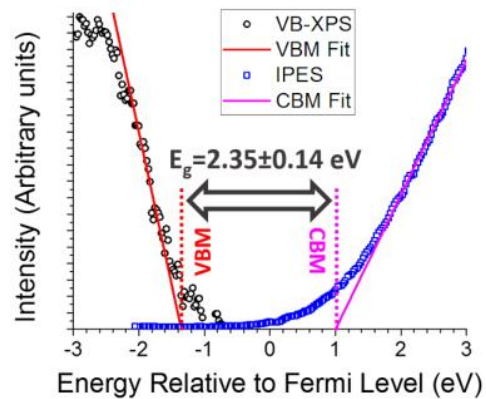

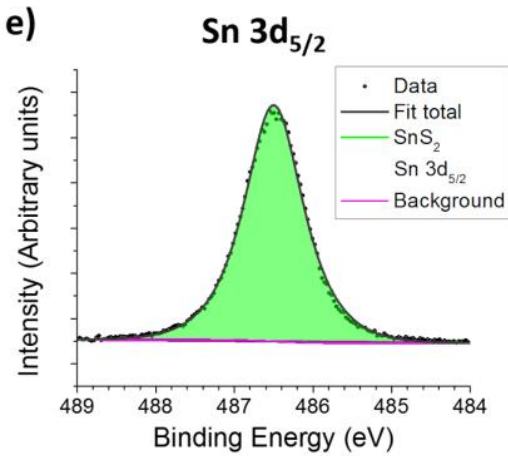

Figure 3 Characterization of $\mathrm{SnS}_{2}$ films. Cross-sectional HAADF-STEM image of a) $\mathrm{SnS}_{2}$ film on $\mathrm{Si}$ and enlarged views of selected areas of the film with $\mathrm{SnS}_{2}$ atomic models projected along the b) [100] and c) [210] directions. d) $\mathrm{SnS}_{2}$ (001) in-plane pole figure. Core-level X-ray photoelectron spectra of e) $\mathrm{Sn} 3 \mathrm{~d}_{5 / 2}$ and f) $\mathrm{S} 2 \mathrm{p}$ regions. g) Determination of band gap from XPS (VB) and IPES (CB) data. The analyzed films were deposited using 500 cycles and annealed at $250^{\circ} \mathrm{C}$.

\subsection{Controlling Film Thickness}

The ability to tailor the film thickness by controlling the number of ALD cycles was further explored. First, as the thickness measurements of sub-10 nm 2D films are crucial, yet challenging, we utilized several methods and found excellent agreement with the values measured by ellipsometry, XRR, XTEM, and atomic force microscopy (AFM), as shown in Figure 4a. The annealed films were continuous and very smooth with roughness close to that of the $\mathrm{Si}$ substrate $\left(\mathrm{R}_{\mathrm{q}} \approx 0.22 \mathrm{~nm}\right)$ when 50 to 500 cycles were applied (Figure $4 \mathrm{~b}$ ), corresponding to thicknesses of approximately 1.2 to $6.5 \mathrm{~nm}$, or 2 to 11 monolayers of $\mathrm{SnS}_{2}$ (thickness of a monolayer $=0.59 \mathrm{~nm}$ ) ${ }^{[40]}$ In contrast, although the as-deposited films deposited with as little as 5 cycles were very smooth (Figure S13, Supporting Information), 


\section{WILEY-VCH}

the thinnest films deposited with 5 to 25 cycles became discontinuous and relatively rough upon annealing (Figure S14, Supporting Information). Thicker films deposited with 1000 or more cycles, on the other hand, partially crystallized already during the film growth, resulting in a rough surface.

Grazing incidence X-ray diffraction (GIXRD) showed a broad peak for the annealed films deposited with as few as 25 cycles, which was assigned to the (001) reflection of $\mathrm{SnS}_{2}$ (Figure 4c and Figure S15, Supporting Information), whereas by Raman spectroscopy crystalline $\mathrm{SnS}_{2}$ was detected in the annealed films deposited with at least 50 cycles (Figure S16, Supporting Information). The broadness of the (001) peak is due to the small film thicknesses, whereas the shift of the peak position to smaller $2 \theta$ angles (compared to bulk value $\left.2 \theta=15.0^{\circ}\right)^{[40]}$ observed for the thinnest films ( $\leq 100$ cycles) seems to imply somewhat increased interlayer spacing. The rather intense (001) peak detected in the asymmetric grazing incidence geometry also indicates that in some of the crystallites the (001) planes were tilted by approximately $6.5^{\circ}$ with respect to the substrate surface, which agrees with the TEM and in-plane pole figure measurements presented earlier. For the thickest film deposited with 500 cycles, a weak (002) peak was also detected, which suggests that in some crystallites in this film the (001) planes were tilted by at least $14^{\circ}$ with respect to the substrate surface.

The out-of-plane orientation was analyzed quantitatively using $\alpha$ scans extracted from the inplane pole figure data (Figure $4 \mathrm{~d}$ and Figure S18, Supporting Information). The thinnest continuous films deposited with 50 to 100 cycles had the strongest (001) out-of-plane texture among our films as is evident from the rapid increase of intensity toward $\alpha=90^{\circ}$, whereas the films deposited with 175 to 500 cycles showed a peak near $\alpha \approx 80^{\circ}$, meaning that in most of the crystallites the (001) planes were tilted by approximately $10^{\circ}$ with respect to the substrate surface (Figure 4e). Comparison of the GIXRD and $\theta-2 \theta$ data, in particular the (001) peak intensities, supports these conclusions (Figure S20, Supporting Information). Additional 


\section{WILEY-VCH}

evidence for the out-of-plane orientation and the crystallinity of even the thinnest films was obtained from in-plane XRD measurements (Figure S21, Supporting Information).

a)

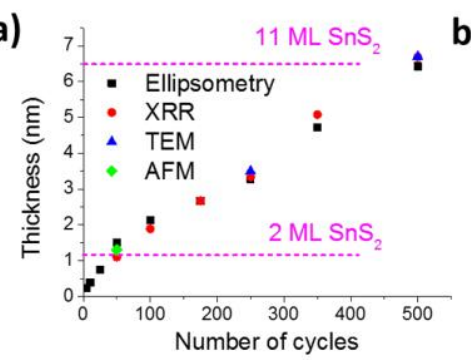

c)

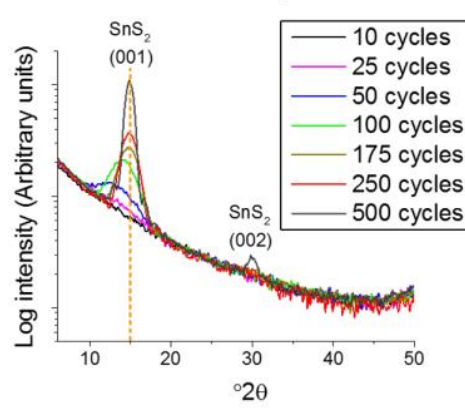

b)

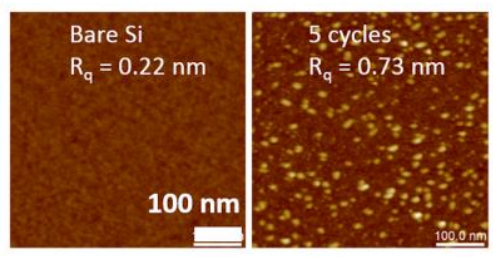

d)

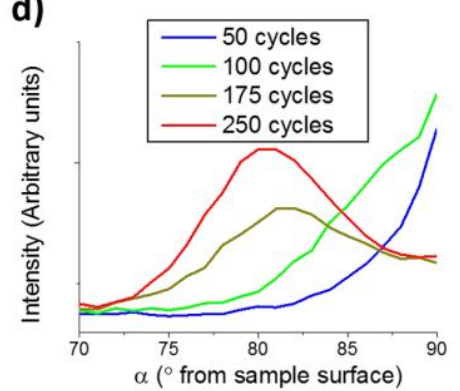

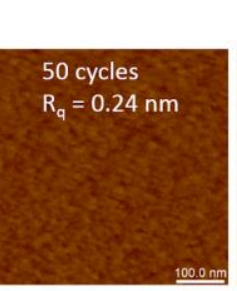

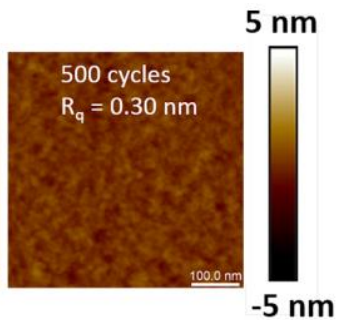

e)

$\alpha \approx 90^{\circ}$

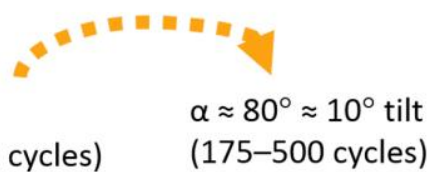

(50-100 cycles)

(175-500 cycles)

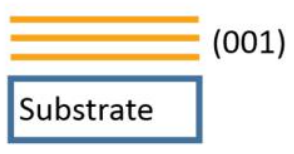

Substrate

Figure 4 Controlling the thickness of annealed films. a) Thickness measurements with different methods. For comparison, the calculated thicknesses for 2 and 11 monolayers of $\mathrm{SnS}_{2}$ are shown. b) AFM images, c) Grazing incidence X-ray diffractograms (orange dashed line indicates the reference position of the (001) peak), and d) (001) a scans of $\mathrm{SnS}_{2}$ films of different thicknesses. e) Schematic illustration of the orientation of the $\mathrm{SnS}_{2}(001)$ planes with varying film thickness. All of the films were annealed at $250{ }^{\circ} \mathrm{C}$. 


\section{WILEY-VCH}

\subsection{Two-Stage Deposition for Improved Texture}

In order to further understand the growth and improve the texture of films thicker than about 2 $\mathrm{nm}$ (100 cycles), we deposited $\mathrm{SnS}_{2}$ films in two stages: first, a thin amorphous layer was deposited using 50 cycles, which was then annealed at $250{ }^{\circ} \mathrm{C}$. The resulting crystalline $\mathrm{SnS}_{2}$ film was used as a seed layer for further growth of $\mathrm{SnS}_{2}$ (Figure 5a). The process was followed by XRD measurements after each step. As expected, the film deposited with 50 cycles appeared amorphous as deposited and crystalline after annealing at $250{ }^{\circ} \mathrm{C}$, although the (001) reflection to was very weak in out-of-plane XRD measurements due to the small film thickness (Figure 5b). Upon further deposition of 200 cycles of $\mathrm{SnS}_{2}$ on the annealed 50 cycle seed layer, the intensity of the (001) reflection increased dramatically, which suggests that $\mathrm{SnS}_{2}$ continues to grow as crystalline material on the crystalline seed layer. This is further supported by the observation that an additional post-deposition annealing step caused little change in $\theta-2 \theta$ and $\omega$ XRD scans (Figure S22, Supporting Information).

Remarkably, as seen in Figure 5b, the intensity of the (001) reflection was strongly increased in $\theta-2 \theta$ XRD compared to a reference film deposited in one step, which implies improved out-of-plane texture. $\alpha$ scan (Figure 5c) and rocking curve ( $\omega$ scan, Figure 5d) measurements further support the greatly improved (001) out-of-plane texture compared to the reference film. A very sharp peak with a full width at half maximum (FWHM) value of only $0.12^{\circ}$ was obtained by the rocking curve measurement, although this was superimposed on a broad peak with a FWHM of approximately 5 degrees suggesting the presence of two populations of crystallites: one with excellent and the other with imperfect (001) out-of-plane orientation. The use of the seed layer somewhat increased film roughness to $0.51 \mathrm{~nm}$ (Figure 5e) compared to $0.26 \mathrm{~nm}$ for a 250 cycle film deposited in one step (Figure S23, Supporting Information). The increased roughness may result from slightly varying growth rates of the individual grains. 
a)
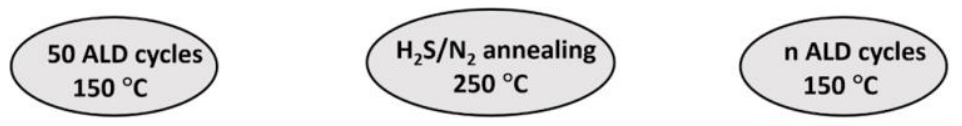

Amorphous

$\mathrm{SnS}_{2}$
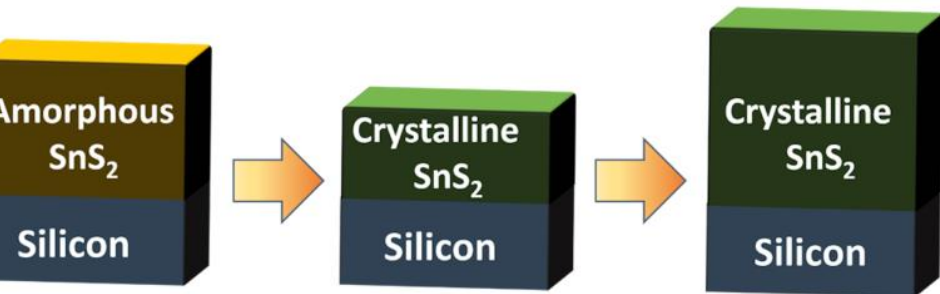

c)

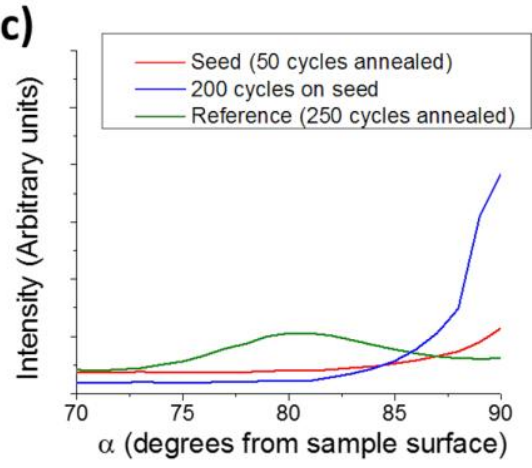

d)

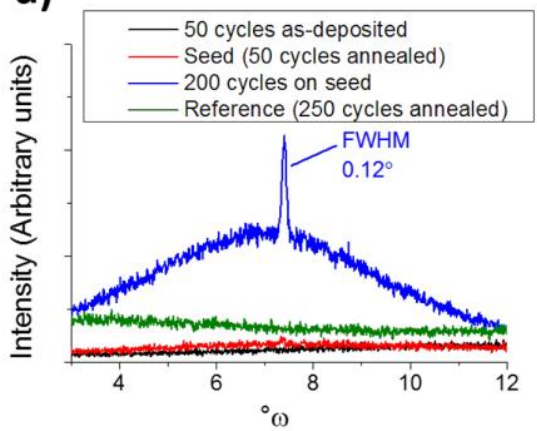

b)

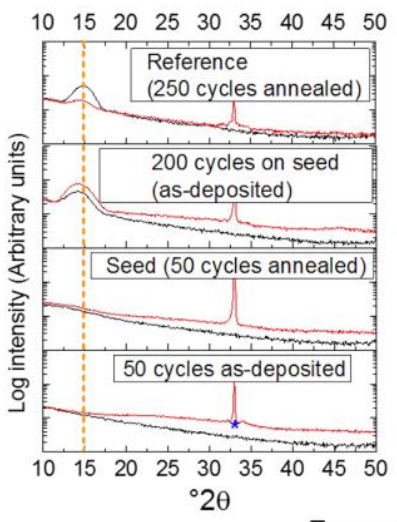

e) $5 \mathrm{~nm}$

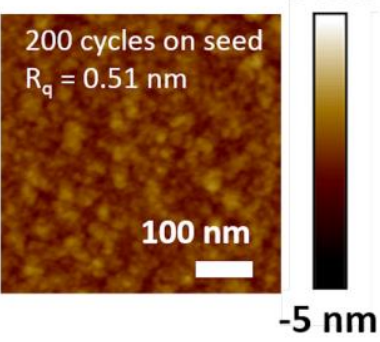

Figure 5 Two-stage deposition of $\mathrm{SnS}_{2}$. a) Schematic illustration of the method, starting with deposition of a thin, amorphous layer, which is subsequently crystallized and used as a seed layer for further growth of $\mathrm{SnS}_{2}$. b) GIXRD (black) and $\theta-2 \theta$ (red) X-ray diffractograms, c) (001) $\alpha$ scans, and d) (001) rocking curves of $\mathrm{SnS}_{2}$ films. e) AFM image of a $\mathrm{SnS}_{2}$ film formed by deposition of 200 cycles on the 50 cycle seed layer. The orange dashed line and the blue asterisks in b) denote the $\mathrm{SnS}_{2}(001)$ and substrate reflections, respectively.

\section{Conclusion}

In this work, we achieved deposition of wafer-scale, two to ten monolayer $\mathrm{SnS}_{2}$ films by combining ALD with post-deposition annealing. Remarkably, the mild annealing at $250{ }^{\circ} \mathrm{C}$ resulted in highly crystalline and smooth $\mathrm{SnS}_{2}$ films. The self-limiting growth characteristics of ALD enabled facile control of film thickness and guaranteed excellent large-area uniformity and conformality of the deposited films. Good crystallinity of the 1T-phase $\mathrm{SnS}_{2}$ films was confirmed by XRD, Raman spectroscopy, and TEM. An application-relevant band gap of $2.35 \pm 0.14 \mathrm{eV}$ was measured for a ten-monolayer film. The present method opens new avenues for the use of $\mathrm{SnS}_{2}$ through scalable, low-temperature deposition of continuous films with readily controlled thickness and should be easily adaptable for both fundamental and applied studies and even industrial use. The smooth and highly crystalline $\mathrm{SnS}_{2}$ films are good candidates for applications in electronics and optoelectronics, among other areas. In a broader 


\section{WILEY-VCH}

context, the results highlight the potential of ALD to bring 2D materials from lab to fab from academic research to industrial production.

\section{Experimental Section}

Film Growth: Tin disulfide thin films were deposited using a commercial, hot wall flow-type F120 ALD reactor operating at a pressure of approximately 5 mbar. ${ }^{[45]}$ Nitrogen $\left(\mathrm{N}_{2}\right.$, AGA, 99.999\%) was used as both carrier and purge gas at a flow rate of $400 \mathrm{sccm}$. The films were deposited on silicon (100), soda lime glass, and $90 \mathrm{~nm} \mathrm{SiO} / / \mathrm{Si}$ substrates (denoted $\mathrm{SiO}_{2} / \mathrm{Si}$ ) with a maximum size of $5 \times 5 \mathrm{~cm}^{2}$, i.e. slightly larger than 2 " wafers. The glass substrates were cleaned in successive ultrasonic baths of alkaline ultrasonic cleaning solution, ethanol, and de-ionized water followed by careful rinsing.

Tin(IV) acetate [Sn(OAc) $\left.)_{4}\right]$ was obtained from Alfa Aesar and evaporated from an open glass boat held at $130{ }^{\circ} \mathrm{C}$ inside the ALD reactor. Hydrogen sulfide $\left(\mathrm{H}_{2} \mathrm{~S}\right.$, Linde, 99.5\%) was supplied into the reactor through needle and solenoid valves at a flow rate of $14 \mathrm{sccm}$. Unless otherwise noted, the films were deposited at $150{ }^{\circ} \mathrm{C}$ using $1 \mathrm{~s} \mathrm{Sn}(\mathrm{OAc})_{4}$ and $4 \mathrm{~s} \mathrm{H}_{2} \mathrm{~S}$ pulses separated by $2 \mathrm{~s} \mathrm{~N}_{2}$ purges.

Post-Deposition Annealing: The films were post-deposition annealed in the F120 ALD reactor, unless otherwise noted. The annealing was performed under flowing $\mathrm{N}_{2}(400 \mathrm{sccm}$, approximately 5 mbar), mixed with $\mathrm{H}_{2} \mathrm{~S}$ pulses $(14 \mathrm{sccm})$ for $1 \mathrm{~h}$ at $250{ }^{\circ} \mathrm{C}$. To avoid damaging the pulsing valves of the reactor with excessively long pulses, $\mathrm{H}_{2} \mathrm{~S}$ was pulsed for 3 $\mathrm{s}$ at a time with a $0.5 \mathrm{~s}$ purge in between the pulses.

Thickness Measurements: Film thicknesses were initially measured by X-ray reflectivity (XRR, PANalytical X'Pert Pro MPD or Rigaku Smartlab). For comparison, and to be able to measure the thinnest films, a Film Sense FS-1 Multi-Wavelength ellipsometer was used. For ellipsometry, simple Cauchy models were used to model the $\mathrm{SnS}_{2}$ and $\mathrm{SiO}_{2}$ layers on the silicon wafer, an assumption which was proven adequate by good agreement between 


\section{WILEY-VCH}

ellipsometry and XRR. The thickness of the native $\mathrm{SiO}_{2}$ layer $(1.8 \mathrm{~nm})$ was measured from an as-received Si wafer and included in the XRR and ellipsometry models. For selected samples, XTEM images or AFM images measured over steps created by gently scratching the films with a needle were used to measure the film thickness.

Morphological Characterization: Film morphology was characterized by atomic force microscopy (AFM, Veeco Multimode V) in tapping mode in air using silicon probes (Bruker) with a nominal tip radius of less than $10 \mathrm{~nm}$. The images were flattened or planefitted to remove artefacts caused by sample tilt and scanner bow. Film roughness was calculated as a root mean square value $\left(\mathrm{R}_{\mathrm{q}}\right)$ from $2 \times 2 \mu \mathrm{m}^{2}$ images.

TEM Imaging: Cross-sectional TEM imaging was performed by Hitachi HD2700 aberration corrected scanning transmission electron microscope (AC-STEM) operated at $200 \mathrm{kV}$ in highangle annular dark-field (HAADF) and bright-field modes. The EDS maps were acquired using a Bruker Quantax EDS detector. The TEM samples were prepared by a FEI Helios 660 Dual-Beam FIB/SEM: a protective carbon layer was initially deposited to protect the area of interest, followed by preparation of a lamella by lift-out method (FIB milling), which was then thinned to electron transparency. The TEM, EDS, and FIB work was performed by EAG Laboratories.

Structure Characterization: Film crystallinity was studied with X-ray diffraction (XRD) using grazing incidence (incident angle $1^{\circ}$ ) or $\theta-2 \theta$ diffraction geometry and $\mathrm{Cu} \mathrm{K} \alpha(\lambda=1.54 \AA) \mathrm{X}$ ray beam. Either a PANalytical X'Pert Pro MPD or a Rigaku Smartlab diffractometer was used with similar parallel beam optics. Additionally, in-plane diffraction ( $2 \theta \chi$ scans, incident angle $0.3^{\circ}$ ) was performed with the Rigaku instrument. Out-of-plane (001) orientation was probed with conventional, out-of-plane $\omega$ scans $\left(2 \theta=14.8^{\circ}\right)$ as well as in-plane pole figures ${ }^{[49]}$ performed with the Rigaku Smartlab instrument. The center of the pole figure is here defined as $\alpha=90^{\circ}$. 


\section{WILEY-VCH}

Micro-Raman spectra were measured in backscattering geometry using a confocal Raman microscope (NT-MDT Ntegra) equipped with a $532 \mathrm{~nm}$ laser and a 100× objective. The laser power on the sample was adjusted to approximately $0.1 \mathrm{~mW}$ and the acquisition time was 600 s. No degradation of the film structure was observed at this laser power. Films grown on 90 $\mathrm{nm} \mathrm{SiO} / \mathrm{Si}$ substrates were used for the Raman measurements due to the well-known optical enhancement effect of such substrates for $2 \mathrm{D}$ materials. ${ }^{[50]}$

Photoelectron Spectroscopy: Photoelectron spectroscopy measurements were performed in an UHV chamber with a base pressure of $1 \times 10^{-10}$ mbar. Core-level and valence band X-ray photoelectron spectroscopy (XPS) was performed using a SPECS monochromated Al Ka source $(\mathrm{h} v=1486.6 \mathrm{eV})$ operating at $250 \mathrm{~W}$ with a PSP Vacuum Technology 5 channeltron hemispherical electron analyzer calibrated to the $\mathrm{Ag} 3 \mathrm{~d}_{5 / 2}$ peak at $386.3 \mathrm{eV}$. By fitting a convoluted Fermi-Dirac distribution to the Ag Fermi level, the resolution was determined to be $0.37 \mathrm{eV}$, which gives an uncertainty of $\pm 0.05 \mathrm{eV}$ for the binding energies. The unoccupied states in the conduction band were probed by inverse photoemission spectroscopy (IPES) using a PSP Vacuum Technology IPES system with a $\mathrm{BaO}$ electron dispenser cathode operated with variable operating voltage and a photon detector with a $\mathrm{SrF}_{2}$ window as a lowpass filter and a NaCl-coated Ta cone as a high-pass filter. The overall resolution of $0.80 \mathrm{eV}$ for the IPES instrument calibrated with the well-defined lowest unoccupied molecular orbital of $\mathrm{C}_{60}$ and the $\mathrm{Ag}$ fermi level gives an uncertainty of $\pm 0.14 \mathrm{eV}$ for the conduction band minimum $(\mathrm{CBM})$ position. The samples were analyzed as received without any sputtering. The valence-band XPS and IPES measurements were done at a $45^{\circ}$ angle with respect to the surface to minimize the contribution from the substrate. XPS core levels of Sn and S were not affected by the measurement angle, and the data shown was measured at $90^{\circ}$ (perpendicular to the substrate). 


\section{WILEY-VCH}

Visualization of Crystal Structures: VESTA software ${ }^{[51]}$ was used for visualization of the structure of $\mathrm{SnS}_{2}$ (JCPDS-ICDD PDF 26-0677) and the precursors $\mathrm{Sn}(\mathrm{OAc})_{4}$ (CCDC 1100658) and $\mathrm{H}_{2} \mathrm{~S}$ (JCPDS-ICDD PDF 85-748).

\section{Supporting Information}

Supporting Information is available from the Wiley Online Library or from the author.

\section{Acknowledgements}

The research was supported by ASM Microchemistry and the Finnish Centre of Excellence in Atomic Layer Deposition funded by the Academy of Finland. TEM sample preparation and imaging as well as EDS measurements were performed by EAG Laboratories. VRD and JTG acknowledge the Engineering and Physical Sciences Research Council (EPSRC) (Grant Nos. EP/J021229/1 and EP/N015800/1) for support.

Received: ((will be filled in by the editorial staff))

Revised: ((will be filled in by the editorial staff)) Published online: ((will be filled in by the editorial staff))

\section{References}

[1] K. S Novoselov, A. K. Geim, S. V. Morozov, D. Jiang, Y. Zhang, S. V. Dubonos, I. V. Grigorieva, A. A. Firsov, Science 2004, 306, 666.

[2] B. Radisavljevic, A. Radenovic, J. Brivio, V. Giacometti, A. Kis, Nat. Nanotechnol. 2011, 6, 147.

[3] X. Zhou, Q. Zhang, L. Gan, H. Li, J. Xiong, T. Zhai, Adv. Sci. 2016, 3, 1600177.

[4] Y. Huang, E. Sutter, J. T. Sadowski, M. Cotlet, O. L. A. Monti, D. A. Racke, M. R. Neupane, D. Wickramaratne, R. K. Lake, B. A. Parkinson, P. Sutter, ACS Nano 2014, 8, 10743.

[5] Gonzalez, J. M.; Oleynik, I. I. Layer-Dependent Properties of $\mathrm{SnS}_{2}$ and $\mathrm{SnSe}_{2}$ TwoDimensional Materials. Phys. Rev. B - Condens. Matter Mater. Phys., 2016, 94, 125443. 


\section{WILEY-VCH}

[6] L. A. Burton, T. J. Whittles, D. Hesp, W. M. Linhart, J. M. Skelton, B. Hou, R. F.

Webster, G. O’Dowd, C. Reece, D. Cherns, D. J. Fermin, T. D. Veal, V. R. Dhanak, A. Walsh, J. Mater. Chem. A 2016, 4, 1312.

[7] G. Ye, Y. Gong, S. Lei, Y. He, B. Li, X. Zhang, Z. Jin, L. Dong, J. Lou, R. Vajtai, W. Zhou, P. M. Ajayan, Nano Res. 2017, 10, 2386.

[8] H. S. Song, S. L. Li, L. Gao, Y. Xu, K. Ueno, J. Tang, Y. B. Cheng, K. Tsukagoshi, Nanoscale 2013, 5, 9666.

[9] G. Su, V. G. Hadjiev, P. E. Loya, J. Zhang, S. Lei, S. Maharjan, P. Dong, P. M. Ajayan, J. Lou, H. Peng, Nano Lett. 2015, 15, 506.

[10] Y. Sun, H. Cheng, S. Gao, Z. Sun, Q. Liu, Q. Liu, F. Lei, T. Yao, J. He, S. Wie, Y. Xie, Angew. Chem. 2012, 124, 8857; Angew. Chem. Int. Ed. Engl.. 2012, 51, 8727.

[11] M.-J. Lee, J.-H. Ahn, J. H. Sung, H. Heo, S. G. Jeon, W. Lee, J. Y. Song, K.-H. Hong, B. Choi, S.-H. Lee, M.-H. Jo, Nat. Commun. 2016, 7, 12011.

[12] Y. Xie, M. Fan, T. Shen, Q. Liu, Y. Chen, Mater. Technol (Abingdon, U. K.) 2016, 31, 646.

[13] J. Z. Ou, W. Ge, B. Carey, T. Daeneke, A. Rotbart, W. Shan, Y. Wang, Z. Fu, A. F. Chrimes, W. Wlodarski, S. P. Russo, Y. X. Li, K. Kalantar-zadeh, ACS Nano 2015, 9, 10313. [14] W. Choi, H. Choudhary, G. H. Han, J. Park, D. Akinwande, Y. H. Lee, Mater. Today 2017, 20, 116 .

[15] H. H. Radamson, Y. Zhang, X. He, H. Cui, J. Li, J. Xiang, J. Liu, S. Gu, G. Wang, Appl. Sci. 2017, 7, 1047.

[16] International Technology Roadmap for Semiconductors 2.0: Executive Report, 2015 Edition, Semiconductor Industry Association.

[17] M. Chhowalla, H. S. Shin, G. Eda, L.-J. Li, K. P. Loh, H. Zhang Nat. Chem. 2013, 5, 263.

[18] W. Zhang, X. Xiao, Y. Li, X. Zeng, L. Zheng, C. Wan, RSC Adv. 2016, 6, 33705. 


\section{WILEY-VCH}

[19] C. Zhai, N. Du, H. Z. D. Yang, Chem. Commun. 2011, 47, 1270.

[20] S. L. Wong, H. Liu, D. Chi, Prog. Cryst. Growth Charact. Mater. 2016, 62, 9.

[21] M. Bosi, RSC Adv. 2015, 8, 75500.

[22] Q. Ji, Y. Zhang, Y. Zhang, Z. Liu, Chem. Soc. Rev. 2015, 44, 2587.

[23] J. H. Li, X. Li, X. H. Wang, J. X. Hu, X. Y. Chu, X. Fang, Z. P. Wei, Surf. Eng. 2016, $32,245$.

[24] K. Kang, S. Xie, L. Huang, Y. Han, P. Y. Huang, K. F. Mak, C.-J. Kim, D. Muller, J. Park, Nature 2015, 520, 656.

[25] E. Singh, K. S. Kim, G. Y. Yeom, H. S. Nalwa, ACS Appl. Mater. Interfaces 2017, 9, 3223.

[26] X. Zhou, Q. Zhang, L. Gan, H. Li, T. Zhai, Adv. Funct. Mater. 2016, 26, 4405.

[27] J.-H. Ahn, M.-J. Lee, H. Heo, J. H. Sung, K. Kim, H. Hwang, M.-H. Jo, Nano Lett. 2015, 15, 3703 .

[28] Y. Hu, T. Chen, X. Wang, L. Ma, R. Chen, H. Zhu, X. Yuan, C. Yan, G. Zhu, H. Lv, J. Liang, Z. Jin, J. Liu, Nano Res. 2017, 10, 1434.

[29] M. Ritala, J. Niinistö, in Chemical Vapour Deposition: Precursors, Processes and Applications, (Eds: A. C. Jones, M. L. Hitchman), Royal Society of Chemistry, Cambridge, U.K. 2009, Ch. 4.

[30] H. C. M. Knoops, S. E. Potts, A. A Bol, W. M. M. Kessels, in Handbook of Crystal Growth, $2^{\text {nd }}$ edition, Vol. 3 (Ed: T. Kuech), Elsevier B.V., Amsterdam, Netherlands 2015, Ch. 27.

[31] M. Leskelä, J. Niinistö, M. Ritala, in Comprehensive Materials Processing, Vol. 4 (Eds: S. Hashmi, D. Cameron), Elsevier B.V., Amsterdam, Netherlands 2014, Ch. 5.

[32] M. Ritala, J. Niinistö, ECS Trans. 2009, 25 (8), 641.

[33] I. J. Raaijmakers, ECS Trans. 2011, 41 (2), 3. 


\section{WILEY-VCH}

[34] W. Seo, S. Shin, G. Ham, J. Lee, S. Lee, H. Choi, H. Jeon, Jpn. J. Appl. Phys. 2017, $56,031201$.

[35] G. Ham, S. Shin, J. Park, H. Choi, J. Kim, Y.-A. Lee, H. Seo, H. Jeon, ACS Appl. Mater. Interfaces 2013, 5, 8889.

[36] J. Lee, J. Lee, G. Ham, S. Shin, J. Park, H. Choi, S. Lee, J. Kim, O. Sul, S. Lee, H. Jeon, AIP Adv. 2017, 7, 025311.

[37] G. Ham, S. Shin, J. Park, J. Lee, H. Choi, S. Lee, H. Jeon, RSC Adv. 2016, 6, 54069.

[38] S. Lee, S. Shin, G. Ham, J. Lee, H. Choi, H. Park, H. Jeon, AIP Adv. 2017, 7, 045307.

[39] S. Haukka, ECS Trans. 2007, 3 (15), 15.

[40] PDF 26-0677, JCPDS-ICDD, International Center for Diffraction Data.

[41] C. Bacaksiz, S. Cahangirov, A. Rubio, R. T. Senger, F. M. Peeters, H. Sahin, Phys. Rev. B - Condens. Matter Mater. Phys. 2016, 93, 125403.

[42] D. G. Mead, J. C. Irwin, Solid State Commun., 1976, 20, 885.

[43] Online CRC Handbook of Chemistry and Physics, 98th ed., http://hbcponline.com, accessed: December, 2017.

[44] R. L. Puurunen, W. Vandervorst, J. Appl. Phys. 2004, 96, 7686.

[45] T. Suntola, Thin Solid Films 1992, 216, 84.

[46] T. J. Whittles, L. A. Burton, J. M. Skelton, A. Walsh, T. D. Veal, V. R. Dhanak, Chem. Mater. 2016, 28, 3718.

[47] Y.-B. Yang, J. K. Dash, A. J. Littlejohn, Y. Xiang, Y. Wang, J. Shi, L. H. Zhang, K. Kisslinger, T.-M. Lu, G.-C. Wang, Cryst. Growth Des. 2016, 16, 961.

[48] D. L. Greenaway, R. Nitsche, Solid State Commun. 1965, 3, 1445.

[49] K. Nagao, E. Kagami, Rigaku J. 2011, 27, 6.

[50] M. M. Benameur, B. Radisavljevic, J. S. Héron, S. Sahoo, H. Berger, A. Kis, Nanotechnology 2011, 22, 125706.

[51] K. Momma, F. Izumi, J. Appl. Crystallogr. 2011, 44, 1272. 